\title{
Prognostic relevance of pre- and postoperative plasma L-lactate measurements in calves with acute abdominal emergencies
}

\author{
C. K. Lausch, ${ }^{1}$ ○ A. Lorch, ${ }^{1}$ S. Giertzuch, ${ }^{1}$ A. Rieger, ${ }^{1}$ (1) G. Knubben-Schweizer, ${ }^{1}$ and F. M. Trefz ${ }^{1,2 *}$ (1) \\ ${ }^{1}$ Clinic for Ruminants with Ambulatory and Herd Health Services at the Centre for Clinical Veterinary Medicine, Ludwig-Maximilians-Universität \\ (LMU) Munich, Sonnenstrasse 16, 85764 Oberschleißheim, Germany \\ ${ }^{2}$ Clinic for Ruminants, Vetsuisse-Faculty, University of Bern, Bremgartenstrasse 109a, 3012 Bern, Switzerland
}

\begin{abstract}
In both human and veterinary medicine, L-lactate is a well-established prognostic biomarker of disease severity and mortality and has also attracted increasing attention in bovine medicine due to the availability and validation of cheap and portable L-lactate analyzers. The aim of the present study was to evaluate the prognostic accuracy of plasma L-lactate measurements in calves with acute abdominal emergencies before and during the initial therapeutic period after surgical intervention. A prospective observational study was carried out involving 83 hospitalized calves up to an age of 7 mo, which required surgical intervention for reasons of an acute abdominal emergency such as gastrointestinal ileus or peritonitis. Plasma L-lactate (L-LAC) concentrations were determined immediately before initiation of surgery and $6,12,24,48$, and 72 h later. The outcome of calves was evaluated 3 mo after discharge by a phone call to the farmer, and a positive outcome was defined if the calf was still alive and the owner was satisfied with the animal's postsurgical progress. A total of $29 \%$ of calves were discharged from the hospital and the proportion of calves with a positive outcome after the 3 -mo period was $24 \%$. At all sampling times during the first $48 \mathrm{~h}$ after initiation of surgical intervention, calves with a negative outcome had significantly higher L-LAC than calves with a positive outcome. A binary logistic regression analysis indicated that the odds for a negative outcome during the 3-mo observation period increased by a factor of 1.23 [95\% confidence interval (CI): 1.04-1.44] for every $\mathrm{mmol} / \mathrm{L}$ increase of L-LAC before initiation of surgical intervention, but by a factor of 5.29 (95\% CI: 1.69-16.6) and 5.92 (95\% CI: 1.29-27.3) at 12 and $24 \mathrm{~h}$, respectively. The largest area under the receiver operating characteristic curve for LLAC was observed at $12 \mathrm{~h}(0.91 ; 95 \%$ CI: 0.83-0.99), and a cut-point of $2.75 \mathrm{mmol} / \mathrm{L}$ was identified that had
\end{abstract}

Received July 7, 2019

Accepted September 28, 2019.

*Corresponding author: Florian.Trefz@vetsuisse.unibe.ch a sensitivity and specificity for predicting a negative outcome of 68 and 100\%, respectively. In conclusion, persistent hyper-L-lactatemia during the early postoperative period is a more reliable indicator for a negative outcome in calves with acute surgical abdominal emergencies than hyper-L-lactatemia before initiation of surgical intervention. Postoperative measurements of L-LAC are therefore a clinically useful tool to identify patients with an increased risk for a negative outcome at an early stage after surgical intervention was carried out.

Key words: calf, ileus, peritonitis, hyper-L-lactatemia, surgical abdominal emergency

\section{INTRODUCTION}

A variety of diseases affecting the abomasum, the intestines, or the abdominal cavity can result in a clinical picture of an acute abdominal emergency in calves, which is characterized by varying degrees of abdominal distension, circulatory or peristaltic disorders, and abdominal pain (Mulon and Desrochers, 2005; Rademacher and Lorch, 2005). Many of these disease conditions require immediate surgical intervention to verify the suspected diagnosis and to save the animal (Nichols and Fecteau, 2018). Previous studies, however, indicate that acute abdominal emergencies in calves are associated with a guarded prognosis with reported mortality rates ranging from 49 to $76 \%$ (Naylor and Bailey, 1987; Iselin et al., 1997; Mulon and Desrochers, $2005)$. For that reason, requirements of high therapeutic expenditures, and animal welfare concerns, it would be desirable to reliably predict the outcome at least at an early postoperative stage of therapy. In our experience, assessment of the prognosis based on clinical, ultrasonographic, and intraoperative findings can be challenging in an individual case and there is interest in objectively detectable prognostic biomarkers that can be additionally used in the clinical management of affected animals.

L-Lactate (L-LAC) is a well-established prognostic biomarker in human and veterinary medicine (Pang 
and Boysen, 2007; Kraut and Madias, 2016; Rosenstein et al., 2018a,b), and has also attracted increasing attention in bovine medicine due to the availability and validation of portable L-LAC analyzers (Burfeind and Heuwieser, 2012; Karapinar et al., 2013; Buczinski et al., 2014). The association between hyper L-lactatemia and a negative outcome of therapy is well documented in critically ill humans and animals suffering from acute abdominal emergencies including cows with right-sided abomasal disorders (Figueiredo et al., 2006; Boulay et al., 2014; Buczinski et al., 2015), dogs with gastric dilatation volvulus (de Papp et al., 1999; Zacher et al., 2010; Green et al., 2011), horses with colitis or intestinal ileus (Johnston et al., 2007; Hashimoto-Hill et al., 2011; Petersen et al., 2016), as well as humans with mesenteric ischemic conditions (Lange and Jäckel, 1994). Hyper L-lactatemia is also a common finding in calves with acute abdominal emergencies, but a recent retrospective analysis involving 587 hospitalized calves indicated that a single preoperative determination of the plasma L-LAC concentration is of limited clinical utility for predicting the outcome of affected animals (Lausch et al., 2019). A recent review of the literature further indicated that a delayed reduction of L-LAC to a physiological level or persistent hyperlactatemia during the initial therapeutic period provided more reliable prognostic information in numerous study populations of critically ill animals than the extent of hyperlactatemia before initiation of therapy (Rosenstein et al., 2018b). In equine medicine this has been especially documented for critically ill neonatal foals (Wotman et al., 2009; Borchers et al., 2013) and horses with colitis and other abdominal emergencies (Tennent-Brown et al., 2010; Hashimoto-Hill et al., 2011). Based on these findings, we hypothesized that repeated measurements of plasma L-LAC concentrations during the initial postoperative course of therapy provide more reliable prognostic information in calves with surgically treated acute abdominal emergencies than a single measurement before initiation of therapy. The aim of the present study was to verify this hypothesis.

\section{MATERIALS AND METHODS}

\section{Calves}

For the purpose of the study, every calf up to an age of 7 mo that was admitted to the Clinic for Ruminants with Ambulatory and Herd Health Services of the Ludwig-Maximilians-Universität Munich between August 2015 and December 2016 was included in this prospective observational study. Calves were selected for the study if they were suffering from an acute abdominal emergency and required immediate surgical intervention for reasons of an abomasal disorder, suspected gastrointestinal ileus, or peritonitis. Calves with abdominal emergencies that were eligible for conservative medical treatment were not included in the study. Our investigation was approved by the Ethics committee of the Centre of Veterinary Clinical Medicine, Ludwig-Maximilians-Universität Munich (permit no. 39-15-01-2015).

\section{Clinical Examination and Treatment}

All calves were treated according to clinic principles. After admission to the hospital, calves were weighed and underwent a thorough clinical examination that included an ultrasonographic examination if deemed necessary by the responsible clinician. After a provisional diagnosis was made, a 16-gauge catheter (Cavafix Certo with Splittocan, B. Braun, Melsungen, Germany) that was shortened to a length of $12 \mathrm{~cm}$ was placed in a jugular vein and secured in place with suture material. For this purpose, the area over the respective jugular vein was clipped, antiseptically prepared, and $1 \mathrm{~mL}$ of a $2 \%$ procaine solution was injected s.c. before catheterization.

Calves were operated in left lateral recumbency (n $=74)$ or in dorsal recumbency if navel structures $(\mathrm{n}=$ 9 ) were affected. Anesthetic induction was performed using xylazine $(0.2 \mathrm{mg} / \mathrm{kg}$ of body mass i.m.) and ketamine $(2 \mathrm{mg} / \mathrm{kg}$ of body mass i.v.) and maintained after intubation with isoflurane. Perioperative treatment of calves included i.v. fluid therapy with constant drip infusions consisting of saline and glucose infusion solutions as well as administration of antibiotics and nonsteroidal drugs as shown in Supplemental Table S1 (https://doi.org/10.3168/jds.2019-17224). Infusions were stopped for 20 min before blood sampling, and the amount of residual solution was weighed. In calves with signs of hypovolemic shock, fluid therapy was already initiated preoperatively. The administered amount of fluid per kilogram of body mass was calculated and recorded. After surgical intervention, calves were treated orally with sodium sulfate $(1 \mathrm{~g} / \mathrm{kg}$ of body mass) and received neostigmine (Konstigmin, Vetoquinol $\mathrm{GmbH}$, Ismaning, Germany) at a dosage of $0.025 \mathrm{mg} / \mathrm{kg}$ of body mass s.c. if deemed necessary by the responsible clinician. Neostigmine administration was initiated when the peritoneum was closed and administered at least 4 times in 3-h intervals. Any additional treatments or minor deviations from the treatment protocol were at the discretion of the responsible clinician when deemed necessary in a specific case. This included i.v. administration of sodium bicarbonate in calves with 
concurrent neonatal diarrhea and D-lactic acidosis or administration of a different antibiotic drug if an anti-infective therapy had already been initiated by the referring veterinarian in the field.

\section{Blood Sampling and Laboratory Analyses}

Blood samples for determination of L-LAC were taken from the catheter immediately before initiation of surgery $(0 \mathrm{~h})$ and $6,12,24,48$, and $72 \mathrm{~h}$ later. In those calves where preoperative i.v. fluid therapy was carried out, plasma L-LAC was additionally evaluated immediately before fluid administration. Concentrations of L-LAC were determined from heparinized blood samples containing potassium fluoride to inhibit glycolysis. Within 30 min after sampling, samples were centrifuged at $1,500 \times g$ for 5 min at room temperature. Plasma was harvested immediately after centrifugation and submitted to an in-house laboratory for determination of L-LAC by means of an automatic analyzing system (Cobas c 311, Roche Diagnostics, Mannheim, Germany) using a combined enzymatic colorimetric test principle (Shimojo et al., 1989) with a minimum limit of quantification of $0.17 \mathrm{mmol} / \mathrm{L}$. Hyper-L-lactatemia was defined as a plasma L-LAC concentration $>2.2$ $\mathrm{mmol} / \mathrm{L}$ (Rosenberger, 1990).

\section{Outcome of Therapy and Follow-Up}

Every clinician was blinded to the postoperative course of L-LAC, and a decision to euthanize a calf was exclusively made on the basis of clinical or intraoperative findings, or both. Economic reasons were not considered in the decision to euthanize a calf, and if the general condition of the calf allowed, a re-laparotomy was performed before euthanasia.

Calves were discharged from the hospital when the feed intake and general condition had normalized. The outcome of the discharged calves was evaluated 3 mo after discharge by a phone call to the farmer. The farmers were asked to provide the following information: whether the calf was alive, whether it was still in the herd, how the calf developed compared with herdmates, and whether the owner was satisfied with the animal's postsurgical progress. If the calf was sold, the owner was asked whether it had reached the current market price. The interviews were performed by the same person (CKL), and every farmer was asked the same questions in the same order using a standardized protocol.

For the purpose of this study, calves were allocated to the group of calves with a positive outcome (PO) if discharged calves were still in the herd, developed at least $75 \%$ as their herdmates, had a satisfied owner, or were sold without discount. In contrast, a negative outcome (NO) of therapy was defined as death or euthanasia during hospitalization or if discharged animals were reported to show a retarded development, had an unsatisfied owner, were sold with discount, or had died within the 3-mo period after discharge from the hospital.

\section{Calculations}

Two different methods were used to assess the dynamics of L-LAC over time. The percentage change of plasma L-lactate concentrations $\left(\boldsymbol{\Delta}_{\%} \mathbf{L}-\mathbf{L} \mathbf{A C}\right)$ in relation to values at $0 \mathrm{~h}$ was calculated as follows: $\Delta_{\%} \mathrm{~L}-\mathrm{LAC}=$ $\left(\mathrm{L}-\mathrm{LAC}_{\text {hour x }}-\mathrm{L}_{-} \mathrm{LAC}_{0 \mathrm{~h}}\right) / \mathrm{L}-\mathrm{LAC}_{0 \mathrm{~h}} \times 100$. Furthermore, the area under the L-lactate concentration-time curve $\left(\mathbf{L}-\mathbf{L} \mathbf{A C}_{\mathrm{AUC}}\right)$ was calculated for different time intervals using the trapezoid method as described by Wilkins et al. (2015). For this purpose, the area for each trapezoid between 2 consecutive sampling times was calculated and summed if necessary to obtain the total L-LAC $\mathrm{AUC}_{\mathrm{AUC}}$ for the respective time interval of interest.

\section{Statistical Analysis}

Statistical analysis was performed using Microsoft Excel (version 2010, Microsoft Corp., Redmond, WA), SPSS (version 24.0, IBM, New York, NY), and GraphPad Prism (version 7.01, GraphPad Software, La Jolla, CA). $P$-Values of $<0.05$ were considered statistically significant. A normal distribution of data was assessed by the Shapiro-Wilk test and visual inspection of QQ plots. Because most of the data were not normally distributed, nonparametric tests were employed and data are presented as medians and interquartile ranges $\left(\mathrm{Q}_{1}{ }^{-}\right.$ $\left.\mathrm{Q}_{3}\right)$. Spearman's coefficients of correlation were calculated to determine associations between parameters.

Mann-Whitney U-tests were used to determine statistically significant differences of L-LAC, $\Delta_{\%} \mathrm{~L}-\mathrm{LAC}$, and L-LAC $\mathrm{AUC}_{\mathrm{A}}$ between calves with $\mathrm{PO}$ and NO. A paired Wilcoxon test was used for the comparison of preoperative L-LAC measurements in calves where fluid therapy was initiated before surgery. The association between L-LAC and a NO was also evaluated using binary logistic regression analysis. For this purpose, odds ratios for every $\mathrm{mmol} / \mathrm{L}$ increase of L-LAC with associated $95 \%$ confidence intervals were calculated for each sampling time. Furthermore, the predictive ability of L-LAC and L-LAC $\mathrm{AUC}_{\mathrm{A}}$ at different sampling times was assessed by means of a receiver operating characteristic (ROC) analysis. This included the calculation of the area under the ROC curve (AUC-ROC) and the associated 95\% confidence intervals as well as the identification of cut-off values that optimized the resulting sensitivity 
and specificity for the prediction of a NO on the basis of the Youden index.

\section{RESULTS}

\section{Study Population}

A total of 83 calves was included in the study. Most of the calves $(\mathrm{n}=76 ; 92 \%)$ were German Fleckvieh, which is the most common dairy breed in Bavaria. Four calves were crossbreds, 2 calves were Holstein-Friesian, and 1 calf belonged to the German Braunvieh breed. The sex was male for 37 calves and female for 44 calves. Two calves were freemartins. The median values $\left(\mathrm{Q}_{1}-\mathrm{Q}_{3}\right)$ for age and body mass of the calves were $5.1(1.4-8.7)$ wk and $70.0(49.1-93.6) \mathrm{kg}$, respectively.

\section{Diagnoses and Outcome of Therapy}

Individual diagnoses and the respective number of affected calves are reported in Table 1. Mesenteric torsion and peritonitis were the most frequent diagnoses. Generalized peritonitis was considered to be related to perforating abomasal ulcers $(\mathrm{n}=4)$, sepsis $(\mathrm{n}=4)$, perforation of intestines $(\mathrm{n}=2)$, infections of intra-abdominal navel structures $(\mathrm{n}=2)$, necrotizing enteritis $(\mathrm{n}=2)$, and had an unknown origin in 1 calf. Local peritonitis was related to contusion $(\mathrm{n}=1)$ and perforation $(\mathrm{n}=1)$ of intestines.

As shown in Figure 1, a total of 59 calves $(71.1 \%$ ) did not survive until hospital discharge, of which 53 calves were euthanized and 6 calves died spontaneously. Three of these calves died intra-operatively. Thirtytwo calves were euthanized during the initial surgical intervention due to generalized peritonitis $(\mathrm{n}=13)$, intestinal or abomasal necrosis $(\mathrm{n}=10)$, atresia coli ( $\mathrm{n}$ $=4$ ), and other inoperable findings including abomasal rupture or ulceration, intestinal perforation, and severe intraabdominal adhesions $(\mathrm{n}=5)$. Another 21 calves were euthanized during the subsequent course of hospitalization due to ongoing or recurrent signs of gastrointestinal ileus or a massive deterioration of the general condition. Seventeen of those calves were suffering from peritonitis, intestinal necrosis, or inoperable intestinal obstructions as diagnosed during a re-laparotomy or an in-house necropsy examination. The remaining 4 calves had a postmortem diagnosis of severe pneumonia $(\mathrm{n}=$ 3 ) and meningitis $(n=1)$.

Based on the follow-up interview, 4 out of 24 discharged calves were allocated to the group of calves with NO as they were reported to show a retarded development and the owner was unsatisfied $(\mathrm{n}=2)$ or the animal was dead $(\mathrm{n}=2)$. Therefore, the overall proportion of calves with a PO was $24 \%(\mathrm{n}=20)$.

\section{Association Between Plasma L-Lactate and Outcome of Therapy}

As shown in Table 2, L-LAC were significantly higher in calves with $\mathrm{NO}$ than in calves with $\mathrm{PO}$ at all sampling times during the first $48 \mathrm{~h}$ after initiation of surgical intervention. A binary logistic regression analysis indicated that the odds ratio for $\mathrm{NO}$ increased by a factor of 1.23 for every $\mathrm{mmol} / \mathrm{L}$ increase of L-LAC at 0 $\mathrm{h}$, but by a factor of 5.29 and 5.92 at 12 and $24 \mathrm{~h}$ after initiation of surgical intervention, respectively (Table 3 ). The relationship between the predicted probability for a NO and L-LAC measured at 0, 6, 12, and 24 $\mathrm{h}$ relative to start of surgical intervention is comparatively visualized in Figure 2.

Results of the ROC analyses and respective cut-off values for L-LAC that optimized the resulting sensitivity and specificity for the prediction of a NO at each sampling time are reported in Table 4. The highest

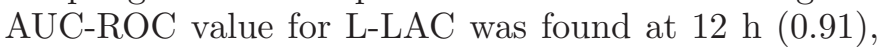

Table 1. Individual intraoperative diagnoses of calves of the present study population $(\mathrm{n}=83)$

\begin{tabular}{|c|c|}
\hline Lesion location and individual diagnosis & No. of calves \\
\hline Abomasum & 15 \\
\hline Right-sided dilatation & 9 \\
\hline Abomasal volvulus & 3 \\
\hline Incarceration $^{1}$ & 1 \\
\hline Rupture $^{2}$ & 1 \\
\hline Ulceration $^{3}$ & 1 \\
\hline Small intestine & 14 \\
\hline Volvulus & 4 \\
\hline Incarceration $^{1}$ & 4 \\
\hline Intussusception & 3 \\
\hline Impaction $^{4}$ & 3 \\
\hline Large intestine & 13 \\
\hline Partial atresia of the colon & 4 \\
\hline Necrotic cecum & 3 \\
\hline Torsio coli or caeci & 2 \\
\hline Intussusception & 2 \\
\hline Dilatatio caeci & 1 \\
\hline Impaction $^{4}$ & 1 \\
\hline Multiple parts & 21 \\
\hline Mesenteric torsion & 16 \\
\hline Bloat/gas colic ${ }^{5}$ & 4 \\
\hline Paralytic ileus & 1 \\
\hline Abdominal cavity & 20 \\
\hline Generalized peritonitis & 15 \\
\hline Intestinal adhesion with obstruction & 3 \\
\hline Local peritonitis & 2 \\
\hline
\end{tabular}

${ }^{1}$ Incarceration in umbilical hernia.

${ }^{2}$ Spontaneous abomasal rupture after a history of right displacement of the abomasum, as described by Rademacher and Lorch (1999) and Roussel et al. (2000).

${ }^{3}$ Scar tissue resulting from a healed abomasal ulcer in the pyloric region that inhibited the passage of abomasal content through the pylorus.

${ }^{4}$ Intraluminal obstruction of the intestines with impaction of feces or feed components.

${ }^{5}$ Characterized by gaseous distension of multiple parts of the gastrointestinal tract. 


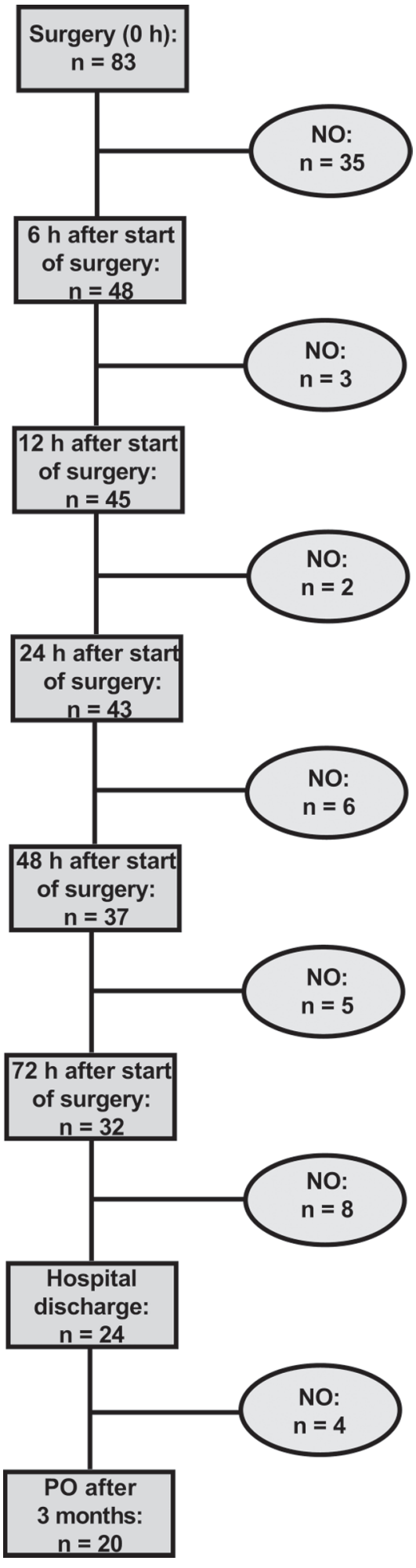

Figure 1. Flowchart illustrating the outcome of therapy of 83 hospitalized calves with acute surgical abdominal emergencies. Ovals to the right indicate the number of calves with a negative outcome (NO) between respective time points. The final outcome of calves was evaluated 3 mo after discharge by a phone call to the farmer, and a positive outcome (PO) was assigned if the calf was still alive and the owner was satisfied with the animal's postsurgical progress. which was higher than for preoperative L-LAC at $0 \mathrm{~h}$ $(0.76)$.

\section{Association Between Changes of Plasma L-Lactate Over Time and Outcome of Therapy}

Calculated values for $\Delta_{\%} \mathrm{~L}$-LAC were not significantly different between calves with $\mathrm{PO}$ and calves with NO (Supplemental Table S2; https://doi.org/10.3168/jds .2019-17224). However, calves with NO had significantly higher values for $\mathrm{L}-\mathrm{LAC}_{\mathrm{AUC}}$ than calves with $\mathrm{PO}$ for each individual interval between consecutive sampling times as well as respective intervals between 0 and $12 \mathrm{~h}$, 0 and $24 \mathrm{~h}, 0$ and $48 \mathrm{~h}$, as well as 0 and $72 \mathrm{~h}$ relative to the onset of surgical intervention (Table 5). Results of subsequent ROC analyses and respective cut-off values for $\mathrm{L}-\mathrm{LAC}_{\mathrm{AUC}}$ that optimized the resulting sensitivity and specificity for the prediction of a NO at each sampling time are also reported in Table 4 .

\section{Association of Infusion Volumes with Plasma L-Lactate}

A total number of 10 calves received i.v. fluid therapy before initiation of surgical intervention due to clinical signs of hypovolemic shock. The median infused volume was $11.8 \mathrm{~mL} / \mathrm{kg}$ of body mass (range: $1.5-34.0 \mathrm{~mL} /$ $\mathrm{kg})$. In those 10 calves, values for L-LAC were not significantly different $(P=0.96)$ between sampling times before initiation of i.v. fluid therapy (median: 9.8; $\mathrm{Q}_{1}-$ $\mathrm{Q}_{3}: 3.80-27.89 \mathrm{mmol} / \mathrm{L}$ ) and $0 \mathrm{~h}$ (median: $10.64 ; \mathrm{Q}_{1}-\mathrm{Q}_{3}$ : $3.72-26.05 \mathrm{mmol} / \mathrm{L})$.

As shown in Supplemental Table S3 (https://doi.org/ 10.3168/jds.2019-17224), L-LAC and calculated values for $\Delta_{\%} \mathrm{~L}-\mathrm{LAC}$ were not significantly correlated with the administered amount of i.v. fluids per kilogram of body mass of calves.

\section{DISCUSSION}

Central findings of this study indicate that hyperL-lactatemia during the initial postoperative period is associated with a markedly increased risk for a NO in hospitalized calves with acute surgical abdominal emergencies. Furthermore, our data indicate that postoperative measurements of L-LAC provide more accurate prognostic information than a single measurement before initiation of therapy. Calves with a NO also had significantly higher values for $\mathrm{L}-\mathrm{LAC}_{\mathrm{AUC}}$, which suggests that not only the magnitude but also the duration of hyper-L-lactatemia during the initial postoperative period is a negative prognostic factor. Those findings confirm our initial hypothesis and are in line to results of previous studies in critically ill foals 
Table 2. Median and interquartile range $\left(\mathrm{Q}_{1}-\mathrm{Q}_{3}\right)$ for plasma L-lactate concentrations $(\mathrm{mmol} / \mathrm{L})$ of calves of the present study population stratified by sampling times and the outcome of therapy ${ }^{1}$

\begin{tabular}{|c|c|c|c|c|c|c|c|}
\hline \multirow[b]{2}{*}{ Sampling time } & \multicolumn{3}{|c|}{ Calves with a positive outcome } & \multicolumn{3}{|c|}{ Calves with a negative outcome } & \multirow[b]{2}{*}{$P$-value } \\
\hline & $\mathrm{n}$ & Median & $\mathrm{Q}_{1}-\mathrm{Q}_{3}$ & $\mathrm{n}$ & Median & $\mathrm{Q}_{1}-\mathrm{Q}_{3}$ & \\
\hline Preoperative $/ 0 \mathrm{~h}$ & 20 & 1.77 & $1.31-4.00$ & 63 & 6.21 & $2.8-10.7$ & 0.001 \\
\hline $6 \mathrm{~h}$ & 20 & 2.02 & $1.26-2.87$ & 28 & 5.00 & $2.81-8.98$ & $<0.001$ \\
\hline $12 \mathrm{~h}$ & 20 & 1.05 & $0.97-1.80$ & 25 & 3.59 & $1.97-8.09$ & $<0.001$ \\
\hline $24 \mathrm{~h}$ & 20 & 1.01 & $0.86-1.13$ & 23 & 1.67 & $1.13-3.84$ & $<0.001$ \\
\hline $48 \mathrm{~h}$ & 20 & 0.76 & $0.71-0.89$ & 17 & 1.14 & $0.92-4.43$ & $<0.001$ \\
\hline $72 \mathrm{~h}$ & 20 & 0.80 & $0.70-0.93$ & 12 & 0.91 & $0.74-1.44$ & 0.14 \\
\hline
\end{tabular}

${ }^{1}$ The outcome of calves was evaluated 3 mo after discharge by a phone call to the farmer, and a positive outcome was assigned if the calf was still alive and the owner was satisfied with the animal's postsurgical progress.

(Borchers et al., 2013; Wilkins et al., 2015), horses with colitis and abdominal emergencies (Tennent-Brown et al., 2010; Hashimoto-Hill et al., 2011), as well as humans with severe sepsis (Arnold et al., 2009), trauma of varied origin (Abramson et al., 1993), and circulatory shock (Vincent et al., 1983), where a delayed return to normo-lactatemia or persistent hyperlactatemia was also documented to represent a more reliable prognostic indicator than hyperlactatemia before initiation of therapy.

In the present study, plasma L-LAC measurements at $12 \mathrm{~h}$ after initiation of surgical intervention provided the most accurate prognostic information. The identified cut-off value of $2.75 \mathrm{mmol} / \mathrm{L}$ was $68 \%$ sensitive and $100 \%$ specific for a NO in this study population and has therefore clinical utility for identification of patients with a markedly increased risk for a $\mathrm{NO}$ at an early stage after surgical intervention. In the light of our findings, we are convinced that the extent of postoperative hyper-lactatemia should however always be seen in the clinical context, and that a thorough clinical evaluation should rather be supplemented than replaced by determination of objective biomarkers. In this context, we consider $12 \mathrm{~h}$ after surgical intervention not only a useful time point for L-LAC measurements, but also for a clinical re-evaluation of the calf and further adaptive therapeutic measures (e.g., administration of fluids or analgesic drugs), as an improvement of clinical signs

Table 3. Results of a univariable binary logistic regression analysis for assessing the association between plasma L-lactate concentrations $(\mathrm{mmol} / \mathrm{L})$ of calves of the present study population at different sampling times and a negative outcome of therapy after a 3-mo observation period

\begin{tabular}{lcccc}
\hline Sampling time & $\mathrm{n}$ & $\mathrm{OR}^{1}$ & $95 \% \mathrm{CI}$ for OR & $P$-value \\
\hline Preoperative/0 h & 83 & 1.23 & $1.04-1.44$ & 0.013 \\
$6 \mathrm{~h}$ & 48 & 1.69 & $1.16-2.48$ & 0.007 \\
$12 \mathrm{~h}$ & 45 & 5.29 & $1.69-16.6$ & 0.004 \\
$24 \mathrm{~h}$ & 43 & 5.92 & $1.29-27.3$ & 0.022 \\
$48 \mathrm{~h}$ & 37 & 128.9 & $1.87-8,901.2$ & 0.025 \\
$72 \mathrm{~h}$ & 32 & 16.0 & $0.40-642.8$ & 0.14 \\
\hline
\end{tabular}

${ }^{1} \mathrm{OR}=$ odds ratio. should already be detectable during this time interval. However, we are aware that a clinical re-evaluation and L-LAC determination after $12 \mathrm{~h}$ is not always practical depending on the time of surgery during the day.

Results of the ROC analyses indicated that calculated values for $\mathrm{L}-\mathrm{LAC}_{\mathrm{AUC}}$ did not provide an advantage in terms of the predictability of a $\mathrm{NO}$ over absolute values for L-LAC at the start or at the end of the respective time interval (Table 4). Therefore, we concluded that the prognostic information of postoperative L-LAC in calves with acute abdominal emergencies is not dependent on repeated consecutive measurements, which facilitates the applicability of our findings. Interestingly, values for $\Delta_{\%} \mathrm{~L}$-LAC were not associated with a NO in calves of the present study population, which was most probably related to the fact that they did not reflect the severity of hyper-L-lactatemia at respective sampling times. Decreased clearance rates of L-LAC after initiation of therapy were associated with a poor prognosis in different study populations of critically ill animals (Stevenson et al., 2007; Tennent-Brown et al., 2010; Borchers et al., 2013). However, the predictive ability of variables that were based on the change of L-LAC relative to baseline values was reported to be inferior to absolute values for L-LAC or calculated areas under the L-LAC concentration time curve in other studies as well (Henderson et al., 2008; Kim et al., 2013; Rosenstein et al., 2018b).

Based on our findings it can be speculated that the relative effect of the underlying pathophysiologic mechanisms for hyper-L-lactatemia changed between the pre- and postoperative phase and that increased LLAC in the postoperative period was probably a more accurate indicator of ischemia-induced injuries and gastrointestinal organ damage. A major contributor to preoperative hyper-L-lactatemia was likely systemic or peripheral hypo-perfusion due to hypovolemia, hypovolemic shock, or mesenteric ischemia, which are all proposed mechanisms for hyperlactatemia due to insufficient tissue oxygen supply, which has traditionally been classified as type A hyperlactatemia (Pang and 
Table 4. Results of a receiver-operating characteristic analysis for assessing the accuracy of plasma L-lactate concentrations at different sampling times and resulting areas under the concentration time curves for the prediction of a negative outcome of therapy in calves of the present study population ${ }^{1}$

\begin{tabular}{|c|c|c|c|c|c|c|}
\hline $\begin{array}{l}\text { Sampling } \\
\text { time }(\mathrm{h})\end{array}$ & $\mathrm{AUC}^{2}$ & $95 \%$ CI for $\mathrm{AUC}$ & $P$-value & Cut-off ${ }^{3}$ & $\begin{array}{c}\text { Sensitivity } \\
(\%)\end{array}$ & $\begin{array}{c}\text { Specificity } \\
(\%)\end{array}$ \\
\hline \multicolumn{7}{|c|}{ Plasma L-lactate concentration } \\
\hline 0 & 0.76 & $0.63-0.88$ & 0.001 & 1.82 & 91 & 60 \\
\hline 12 & 0.91 & $0.83-0.99$ & $<0.001$ & 2.75 & 68 & 100 \\
\hline 24 & 0.81 & $0.68-0.95$ & $<0.001$ & 1.35 & 70 & 90 \\
\hline 48 & 0.84 & $0.70-0.98$ & $<0.001$ & 0.97 & 71 & 90 \\
\hline 6 to 12 & 0.86 & $0.75-0.97$ & $<0.001$ & 20.1 & 68 & 95 \\
\hline 12 to 24 & 0.88 & $0.77-0.98$ & $<0.001$ & 20.2 & 74 & 85 \\
\hline 24 to 48 & 0.82 & $0.67-0.98$ & 0.001 & 23.5 & 88 & 75 \\
\hline 48 to 72 & 0.72 & $0.52-0.91$ & 0.043 & 21.0 & 83 & 70 \\
\hline 0 to 12 & 0.83 & $0.71-0.95$ & $<0.001$ & 42.5 & 72 & 85 \\
\hline 0 to 24 & 0.85 & $0.74-0.96$ & $<0.001$ & 71.9 & 70 & 95 \\
\hline 0 to 48 & 0.87 & $0.74-0.99$ & $<0.001$ & 96.0 & 77 & 95 \\
\hline
\end{tabular}

${ }^{1}$ The outcome of calves was evaluated 3 mo after discharge by a phone call to the farmer, and a positive outcome was assigned if the calf was still alive and the owner was satisfied with the animal's postsurgical progress.

${ }^{2} \mathrm{AUC}=$ area under the receiver operating characteristic curve.

${ }^{3}$ Value that optimized the resulting sensitivity and specificity on the basis of the Youden index.

Boysen, 2007; Rosenstein et al., 2018a). Considering the reported plasma half-life for L-LAC of 20 to $60 \mathrm{~min}$ in humans and animals (Orringer et al., 1977; Pieschl et al., 1992; De Pedro et al., 2012), hyperlactatemia secondary to hypovolemia and tissue hypoxia should have been rapidly resolved in response to i.v. fluid therapy
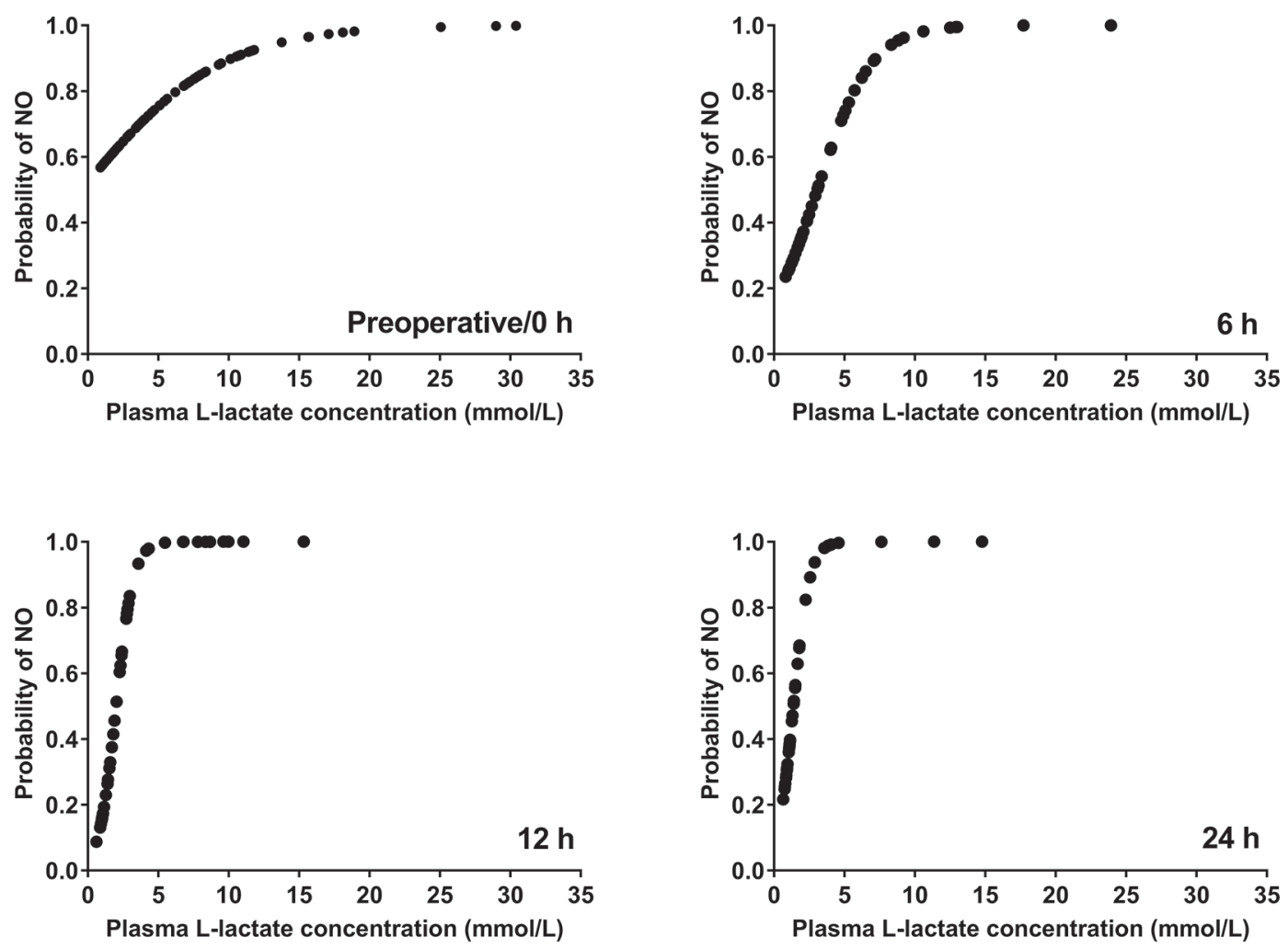

Figure 2. Relationship between plasma L-lactate concentrations of calves of the present study population measured $0,6,12$, and $24 \mathrm{~h}$ relative to the onset of surgical intervention and the predicted probability of a negative outcome (NO) of therapy at the end of a 3-mo observation period. 
and surgical intervention. Postoperative hyperlactatemia was therefore more likely related to dysmetabolism and poor oxygen utilization by tissues in the face of adequate oxygen delivery, which has traditionally been classified as type B hyperlactatemia (Cohen et al., 1976; Pang and Boysen, 2007).

A possible explanation for postoperative hyper-Llactatemia in calves with a NO was likely endotoxemia and sepsis due to gastrointestinal organ damage and a concomitant dysfunction of the blood-gut barrier as indicated by the results of necropsy examinations or intraoperative findings of calves that underwent relaparotomy. Endotoxemia and sepsis are well-known contributors to hyperlactatemia (Tennant et al., 1973; Corley et al., 2005; Gomez et al., 2019) as they can lead to microcirculatory dysfunction (Ince, 2005), sequestration of leukocytes with increased glucose turnover during oxidative burst (Haji-Michael et al., 1999), and altered cellular respiration. The latter has been related to a phenomenon called cytopathic hypoxia and was also observed during in vitro studies of cells that were exposed to pro-inflammatory cytokines (Fink, 2002). Cytopathic hypoxia occurs in spite of normal blood oxygen saturation and is induced by reactive oxygen species such as nitric oxide, which are produced in excess during sepsis or reperfusion (Taylor et al., 1995; Brealey et al., 2002). Reactive oxygen species impair the activity of enzymes of mitochondrial respiration, which results in an increased accumulation of pyruvate that is eventually converted to L-LAC (Vary, 1996; Fink, 2002).

Reperfusion injury might represent another possible mechanism for persistent hyperlactatemia or even a postoperative increase in L-LAC, which is related to complex biochemical processes that are initiated during ischemia and activated with reperfusion. Experimental studies in horses indicated that microvascular damages during the ischemic phase result in an increase in capillary permeability and occurrence of local edema after restoration of blood flow (Faleiros et al., 2001). The resulting increase of pressure in the surrounding tissues can lead to microcirculatory dysfunction and reduced blood flow, which can initiate a vicious cycle with ongoing hypoxia and production of L-LAC (Moore et al., 1994). Also endotoxemia as a result of progressive luminal and cryptic epithelial cell detachment and degeneration of the lamina propria was observed in horses with experimentally induced reperfusion syndrome (Moore et al., 1981) and might therefore have contributed to a postoperative increase of L-LAC. The relative importance of these potential mechanisms remains speculative and further studies are therefore warranted to gain insights into pathophysiological events that contribute to postoperative hyper-L-lactatemia in calves with acute surgical abdominal emergencies. Future studies may also be added that aim to assess whether multivariable models based on standardized clinical and potentially other biochemical variables allow a more accurate prediction of the outcome of therapy. We did not elect to do such an analysis in the present manuscript as the focus of this study was to assess how postoperative L-LAC measurements can be used as objectively determinable prognostic indicators in the clinical management of calves with acute abdominal emergencies.

A future study is also definitely warranted to validate the identified cut-off value for L-LAC in a distinct and potentially larger population, which should be ideally performed in a field or on-farm setting. The present study is based on a university hospital population, which might be considered as a limitation as such populations are usually preselected toward more severely affected cases. This issue is reflected by the low proportion of calves with a $\mathrm{PO}$, which was in line with previous studies with comparable study populations where mortality rates between 49 to $76 \%$ were reported

Table 5. Comparison of area under the time curves of plasma L-lactate concentration $(\mathrm{mmol} / \mathrm{L} \times \mathrm{h})$ between calves with a positive and a negative outcome of therapy at the end of a 3 -mo observation period ${ }^{1}$

\begin{tabular}{|c|c|c|c|c|c|c|c|}
\hline \multirow{2}{*}{$\begin{array}{l}\text { Sampling } \\
\text { time }(\mathrm{h})\end{array}$} & \multicolumn{3}{|c|}{ Calves with a positive outcome } & \multicolumn{3}{|c|}{ Calves with a negative outcome } & \multirow[b]{2}{*}{$P$-value } \\
\hline & $\mathrm{n}$ & Median & $\mathrm{Q}_{1}-\mathrm{Q}_{3}$ & $\mathrm{n}$ & Median & $\mathrm{Q}_{1}-\mathrm{Q}_{3}$ & \\
\hline 0 to 6 & 20 & 11.7 & $8.4-21.9$ & 28 & 35.1 & $20.5-58.5$ & $<0.001$ \\
\hline 6 to 12 & 20 & 10.7 & $6.5-14.1$ & 25 & 24.6 & $13.7-51.4$ & $<0.001$ \\
\hline 12 to 24 & 20 & 12.5 & $11.1-18.2$ & 23 & 36.0 & $19.0-77.2$ & $<0.001$ \\
\hline 24 to 48 & 20 & 21.9 & $19.3-24.2$ & 17 & 32.5 & $24.9-81.2$ & 0.001 \\
\hline 48 to 72 & 20 & 18.4 & $16.8-22.7$ & 12 & 22.9 & $21.6-34.0$ & 0.044 \\
\hline 0 to 12 & 20 & 23.3 & $14.9-37.7$ & 25 & 56.8 & $35.0-103.1$ & $<0.001$ \\
\hline 0 to 24 & 20 & 41.5 & $27.6-52.3$ & 23 & 91.2 & $50.3-209.4$ & $<0.001$ \\
\hline 0 to 48 & 20 & 60.5 & $50.0-81.6$ & 17 & 132.0 & $93.2-264.1$ & $<0.001$ \\
\hline 0 to 72 & 20 & 77.8 & $70.8-100.0$ & 12 & 125.0 & 103.7-188.3 & 0.001 \\
\hline
\end{tabular}

${ }^{1}$ Values were calculated for different time intervals during the first $72 \mathrm{~h}$ relative to the onset of surgical intervention using the trapezoid method and are presented as median and interquartile ranges $\left(\mathrm{Q}_{1}-\mathrm{Q}_{3}\right)$. 
(Naylor and Bailey, 1987; Mulon and Desrochers, 2005; Lausch et al., 2019). The outcome of our analyses was also potentially influenced by any pretreatment activities in the field and the necessity to already initiate i.v. fluid therapy in a subset of calves with clinical signs of hypovolemic shock before surgery, although the latter practice had no significant effect on the observed L-LAC at $0 \mathrm{~h}$ in those calves. Another potential limitation is the high proportion of calves that were euthanized during initial surgery or the subsequent postoperative period. Although euthanasia appeared to be justified for medical or animal welfare reasons in every case and was supported by intra-operative or postmortem findings, it cannot be completely ruled out that some calves would have recovered with intensive and high-cost therapy. The large variety of individual diagnoses of calves of the present study population might be considered as another shortcoming as it prevented any meaningful analyses on the individual diagnosis level. However, in light of the aforementioned pathophysiological mechanisms that are potentially responsible for persistent hyper-L-lactatemia after surgical intervention, we believe that the effect of the individual diagnosis on the predictive accuracy of L$\mathrm{LAC}$ is lower in a postoperative than in a preoperative situation. This is supported by the observed AUC-ROC of 0.91 for L-LAC measured at $12 \mathrm{~h}$ after initiation of surgery. Another potential limitation was the i.v. fluid protocol used that was obviously not standardized on the BW level of calves, and might therefore have had an effect on the observed clearance rates of L-LAC. This was, however, not supported by the results of the correlation analyses between L-LAC and $\Delta_{\%}$ L-LAC at respective sampling times and the amount of i.v. fluids per kilogram of body mass that were administered during respective time intervals (Supplemental Table S3; https://doi.org/10.3168/jds.2019-17224). Furthermore, standardized infusion rates would have required the use of infusion pumps, which was not performed in the present study to allow the transferability of our results into a field practice situation.

\section{CONCLUSIONS}

Hyper-L-lactatemia during the initial postoperative period is a more reliable prognostic indicator in calves with acute abdominal emergencies than hyperL-lactatemia before initiation of surgery. In the present study, plasma L-LAC concentrations determined after a period of $12 \mathrm{~h}$ following initiation of surgical intervention provided the most accurate prognostic information and an identified cut-off value of $>2.75 \mathrm{mmol} / \mathrm{L}$ had a sensitivity and specificity of 68 and $100 \%$ for predicting a NO, respectively. Postoperative measurements of
L-LAC are therefore a clinically useful monitoring tool that can help to identify patients with a high mortality risk at an early stage after surgical intervention.

\section{ACKNOWLEDGMENTS}

The authors thank all clinicians and staff members at the Clinic for Ruminants with Ambulatory and Herd Health Services (LMU Munich, Germany) who dealt with the clinical cases for their assistance.

\section{REFERENCES}

Abramson, D., T. M. Scalea, R. Hitchcock, S. Z. Trooskin, S. M. Henry, and J. Greenspan. 1993. Lactate clearance and survival following injury. J. Trauma 35:584-588.

Arnold, R. C., N. I. Shapiro, A. E. Jones, C. Schorr, J. Pope, E. Casner, J. E. Parrillo, R. P. Dellinger, and S. Trzeciak. 2009. Multicenter study of early lactate clearance as a determinant of survival in patients with presumed sepsis. Shock 32:35-39.

Borchers, A., P. A. Wilkins, P. M. Marsh, J. E. Axon, J. Read, C. Castagnetti, L. Pantaleon, C. Clark, L. Qura'n, R. Belgrave, C. Schwarzwald, M. Levy, D. Bedenice, M. N. Saulez, and R. C. Boston. 2013. Sequential L-lactate concentration in hospitalised equine neonates: A prospective multicentre study. Equine Vet. J. Suppl. 45:2-7.

Boulay, G., D. Francoz, E. Dore, S. Dufour, M. Veillette, M. Badillo, A. M. Belanger, and S. Buczinski. 2014. Preoperative cow-side lactatemia measurement predicts negative outcome in Holstein dairy cattle with right abomasal disorders. J. Dairy Sci. 97:212-221.

Brealey, D., M. Brand, I. Hargreaves, S. Heales, J. Land, R. Smolenski, N. A. Davies, C. E. Cooper, and M. Singer. 2002. Association between mitochondrial dysfunction and severity and outcome of septic shock. Lancet 360:219-223.

Buczinski, S., G. Boulay, and D. Francoz. 2015. Preoperative and postoperative L-lactatemia assessment for the prognosis of right abomasal disorders in dairy cattle. J. Vet. Intern. Med. 29:375-380.

Buczinski, S., E. Doré, G. Boulay, and D. Francoz. 2014. Validation of the handheld Lactate-Pro analyzer for measurement of blood L-lactate concentration in cattle. Vet. Clin. Pathol. 43:567-572.

Burfeind, O., and W. Heuwieser. 2012. Validation of handheld meters to measure blood L-lactate concentration in dairy cows and calves. J. Dairy Sci. 95:6449-6456.

Cohen, R. D., H. F. Woods, and H. A. Krebs. 1976. Clinical and biochemical aspects of lactic acidosis. Blackwell Scientific Publications, Oxford, UK.

Corley, K. T. T., L. L. Donaldson, and M. O. Furr. 2005. Arterial lactate concentration, hospital survival, sepsis and SIRS in critically ill neonatal foals. Equine Vet. J. 37:53-59.

de Papp, E., K. Drobatz, and D. Hughes. 1999. Plasma lactate concentration as a predictor of gastric necrosis and survival among dogs with gastric dilatation-volvulus: 102 cases (1995-1998). J. Am. Vet. Med. Assoc. 215:49-52.

De Pedro, P., P. A. Wilkins, M. A. McMichael, L. Dirikolu, K. M. Lascola, S. C. Clark-Price, and R. C. Boston. 2012. Exogenous L-lactate clearance in adult horses. J. Vet. Emerg. Crit. Care (San Antonio) 22:564-572.

Faleiros, R. R., G. E. S. Alves, R. L. Santos, A. P. Marques Junior., and D. G. Macoris. 2001. Experimental ischemia and reperfusion in equine small colon. Arq. Bras. Med. Vet. Zootec. 53:341-350.

Figueiredo, M. D., D. V. Nydam, G. A. Perkins, H. M. Mitchell, and T. J. Divers. 2006. Prognostic value of plasma L-lactate concentration measured cow-side with a portable clinical analyzer in Holstein dairy cattle with abomasal disorders. J. Vet. Intern. Med. 20:1463-1470.

Fink, M. P. 2002. Bench-to-bedside review: Cytopathic hypoxia. Crit. Care 6:491-499. 
Gomez, D. E., J. C. Rodriguez-Lecompte, J. Lofstedt, L. G. Arroyo, R. Nino-Fong, and J. T. McClure. 2019. Detection of endotoxin in plasma of hospitalized diarrheic calves. J. Vet. Emerg. Crit. Care (San Antonio) 29:166-172.

Green, T. I., C. C. Tonozzi, R. Kirby, and E. Rudloff. 2011. Evaluation of initial plasma lactate values as a predictor of gastric necrosis and initial and subsequent plasma lactate values as a predictor of survival in dogs with gastric dilatation-volvulus: 84 dogs (20032007). J. Vet. Emerg. Crit. Care (San Antonio) 21:36-44.

Haji-Michael, P. G., L. Ladrière, A. Sener, J.-L. Vincent, and W. J. Malaisse. 1999. Leukocyte glycolysis and lactate output in animal sepsis and ex vivo human blood. Metabolism 48:779-785.

Hashimoto-Hill, S., K. G. Magdesian, and P. H. Kass. 2011. Serial measurement of lactate concentration in horses with acute colitis. J. Vet. Intern. Med. 25:1414-1419.

Henderson, I. S. F., R. P. Franklin, P. A. Wilkins, and R. C. Boston. 2008. Association of hyperlactatemia with age, diagnosis, and survival in equine neonates. J. Vet. Emerg. Crit. Care (San Antonio) 18:496-502.

Ince, C. 2005. The microcirculation is the motor of sepsis. Crit. Care 9:S13-S19.

Iselin, U., C. J. Lischer, H. Stocker, and A. L. Steiner. 1997. Kolik beim Kalb, eine retrospektive Studie über 40 Fälle. Wien. Tierarztl. Monatsschr. 84:20-25.

Johnston, K., S. J. Holcombe, and J. G. Hauptman. 2007. Plasma lactate as a predictor of colonic viability and survival after $360^{\circ}$ volvulus of the ascending colon in horses. Vet. Surg. 36:563-567.

Karapinar, T., O. Kaynar, A. Hayirli, and M. Kom. 2013. Evaluation of 4 point-of-care units for the determination of blood L-lactate concentration in cattle. J. Vet. Intern. Med. 27:1596-1603.

Kim, Y. A., E.-J. Ha, W. K. Jhang, and S. J. Park. 2013. Early blood lactate area as a prognostic marker in pediatric septic shock. Intensive Care Med. 39:1818-1823.

Kraut, J. A., and N. E. Madias. 2016. Lactic acidosis: Current treatments and future directions. Am. J. Kidney Dis. 68:473-482.

Lange, H., and R. Jäckel. 1994. Usefulness of plasma lactate concentration in the diagnosis of acute abdominal disease. Eur. J. Surg. 160:381-384

Lausch, C. K., A. Lorch, G. Knubben-Schweizer, A. Rieger, and F. M. Trefz. 2019. Prognostic value of preoperative plasma L-lactate concentrations in calves with acute abdominal emergencies. J. Dairy Sci. 102:10202-10212.

Moore, J. N., N. A. White, J. N. Berg, C. M. Trim, and H. E. Garner. 1981. Endotoxemia following experimental intestinal strangulation obstruction in ponies. Can. J. Comp. Med. 45:330-332.

Moore, R. M., W. Muir, A. Bertone, and W. Beard. 1994. Characterization of the hemodynamic and metabolic alterations in the large colon of horses during low-flow ischemia and reperfusion. Am. J. Vet. Res. 55:1444-1453.

Mulon, P.-Y., and A. Desrochers. 2005. Surgical abdomen of the calf. Vet. Clin. North Am. Food Anim. Pract. 21:101-132.

Naylor, J. M., and J. V. Bailey. 1987. A retrospective study of 51 cases of abdominal problems in the calf: Etiology, diagnosis and prognosis. Can. Vet. J. 28:657-662.

Nichols, S., and G. Fecteau. 2018. Surgical management of abomasal and small intestinal disease. Veterinary Clinics: Food Animal Practice 34:55-81.

Orringer, C. E., J. C. Eustace, C. D. Wunsch, and L. B. Gardner. 1977. Natural history of lactic acidosis after grand-mal seizures. N. Engl. J. Med. 297:796-799.

Pang, D. S., and S. Boysen. 2007. Lactate in veterinary critical care: Pathophysiology and management. J. Am. Anim. Hosp. Assoc. 43:270-279.

Petersen, M. B., A. Tolver, L. Husted, T. H. Tølbøll, and T. H. Pihl. 2016. Repeated measurements of blood lactate concentration as a prognostic marker in horses with acute colitis evaluated with classification and regression trees (CART) and random forest analysis. Vet. J. 213:18-23.

Pieschl, R. L., P. W. Toll, D. E. Leith, L. J. Peterson, and M. R. Fedde. 1992. Acid-base changes in the running greyhound: contributing variables. J. Appl. Physiol. 73:2297-2304.

Rademacher, G., and A. Lorch. 1999. Labmagenruptur beim Rind. Tierarztl. Umsch. 54:127-133.

Rademacher, G., and A. Lorch. 2005. Das Rind mit Kolik als Patient in der Praxis. Tierarztl. Umsch. 60:236-249.

Rosenberger, G. 1990. Die Klinische Untersuchung des Rindes. Parey, Berlin, Germany.

Rosenstein, P. G., B. S. Tennent-Brown, and D. Hughes. 2018a. Clinical use of plasma lactate concentration. Part 1: Physiology, pathophysiology, and measurement. J. Vet. Emerg. Crit. Care (San Antonio) 28:85-105.

Rosenstein, P. G., B. S. Tennent-Brown, and D. Hughes. 2018b. Clinical use of plasma lactate concentration. Part 2: Prognostic and diagnostic utility and the clinical management of hyperlactatemia. J. Vet. Emerg. Crit. Care (San Antonio) 28:106-121.

Roussel, A. J., N. D. Cohen, and R. N. Hooper. 2000. Abomasal displacement and volvulus in beef cattle: 19 cases (1988-1998). J. Am. Vet. Med. Assoc. 216:730-733.

Shimojo, N., K. Naka, C. Nakajlma, C. Yoshikawa, K. Okuda, and K. Okada. 1989. Test-strip method for measuring lactate in whole blood. Clin. Chem. 35:1992-1994.

Stevenson, C. K., B. A. Kidney, T. Duke, E. C. R. Snead, R. C. Mainar-Jaime, and M. L. Jackson. 2007. Serial blood lactate concentrations in systemically ill dogs. Vet. Clin. Pathol. 36:234-239.

Taylor, D. E., A. J. Ghio, and C. A. Piantadosi. 1995. Reactive Oxygen Species Produced by Liver Mitochondria of Rats in Sepsis. Arch. Biochem. Biophys. 316:70-76.

Tennant, B., M. Reina-Guerra, and D. Harrold. 1973. Metabolic response of calves following acute experimental endotoxemia. Ann. Rech. Vétér. 4:135-147.

Tennent-Brown, B. S., P. A. Wilkins, S. Lindborg, G. Russell, and R. C. Boston. 2010. Sequential plasma lactate concentrations as prognostic indicators in adult equine emergencies. J. Vet. Intern. Med. 24:198-205.

Vary, T. C. 1996. Sepsis-induced alerations in pyruvate dehydrogenase complex activity in rat skeletal muscle: Effects on plasma lactate. Shock 6:89-94.

Vincent, J.-L., P. Dufaye, J. Berre, M. Leeman, J.-P. Degaute, and R. J. Kahn. 1983. Serial lactate determinations during circulatory shock. Crit. Care Med. 11:449-451.

Wilkins, P. A., B. J. Sheahan, K. A. Vander Werf, C. Castagnetti, J. Hardy, A. Schoster, and R. C. Boston. 2015. Preliminary investigation of the area under the l-lactate concentration-Time curve (LACAREA) in critically ill equine neonates. J. Vet. Intern. Med. 29:659-662.

Wotman, K., P. A. Wilkins, J. E. Palmer, and R. C. Boston. 2009. Association of blood lactate concentration and outcome in foals. J. Vet. Intern. Med. 23:598-605.

Zacher, L. A., J. Berg, S. P. Shaw, and R. K. Kudej. 2010. Association between outcome and changes in plasma lactate concentration during presurgical treatment in dogs with gastric dilatation-volvulus: 64 cases (2002-2008). J. Am. Vet. Med. Assoc. 236: 892-897.

\section{ORCIDS}

C. K. Lausch $\odot$ https://orcid.org/0000-0001-5350-4702

A. Rieger (๑) https://orcid.org/0000-0002-6826-4497

F. M. Trefz @ https://orcid.org/0000-0002-9784-8889 